$$
\begin{array}{r}
\text { "INDIGITADO ESTRUPÍCIC } \\
\text { ARQUEOLOGIA E SIGNIFICAD } \\
\text { ACERCA DO MURO } \\
\text { FORTE DO PRESÉI } \\
\text { (BELÉM-PA }
\end{array}
$$




\section{"INDIGITADO ESTRUPÍCIO": ARQUEOLOGIA E SIGNIFICADOS ACERCA DO MURO DO FORTE DO PRESÉPIO (BELÉM-PARÁ)}




\title{
"INDIGITADO ESTRUPÍCIO": ARQUEOLOGIA E SIGNIFICADOS ACERCA DO MURO DO FORTE DO PRESÉPIO (BELÉM, PA)
}

\section{Resumo}

Entre os anos de 1999 e 2002, o Forte do Presépio em Belém (PA), foi alvo de pesquisas multidisciplinares voltadas ao seu restauro e adequação com vias à sua musealização na conjuntura do Projeto Feliz Lusitânia. Uma das ciências que se dedicou a essa investigação foi a arqueologia, tendo tido uma atuação significativa na condução desse projeto. Durante esse processo, uma questão tomou dimensões exteriores à pesquisa arqueológica: a derrubada de um muro que se afigurava entre a rua e a fortificação. Neste contexto, o muro foi considerado uma "fantasmagoria" que impedia a antiga simbiose entre a fortaleza e a cidade. Contudo, a demolição da muralha foi uma decisão tomada à revelia da equipe de arqueologia, mas de acordo com os interesses estético-funcionais do plano museológico. Para justificar essa ação, uma série de atribuições de sentidos foram dadas ao referido artefato ("indigitado estrupício", "estrovenga", "aberração"). Isto posto, este trabalho pretende debater dois aspectos: (a) os significados dados ao muro, entendido como artefato capaz de suscitar "maneiras distintas de ver e agir no mundo"; e (b) o posicionamento efetivo da equipe de arqueologia diante da derrubada do muro.

Palavras-chave: Antropologia da arqueologia, Forte do Presépio, patrimônio histórico.

\section{"INDIGITADO ESTRUPÍCIO": ARCHEOLOGY AND MEANINGS REGARDING THE FORTE DO PRESÉPIO WALL (BELÉM, PA)}

\begin{abstract}
During the years 1999 and 2002, the Fort of Nativity in Belém, Pará state, was the target of multidisciplinary research for its restoration and adaptation for its further musealization, according to "Feliz Lusitania" project. One of the sciences that are devoted to this research is the archeology, having a significant role in driving this project. During this process, a specific subject, which did not respect to archaeological research, took a great dimension: the overthrow of a wall that appeared between the street and fortification. In this context, the wall was considered a "phantasmagoria" that prevented the ancient symbiosis between the fortress and the city. However, the demolition of the wall was a decision made behind the backs of archeology team, but according to the aesthetic and functional interests of the museum plan. To justify this action, a series of assignments were given to that artifact ("Indignant conflict", "aberration", "freak"). This paper aims to discuss two aspects: (a) the meanings given to the wall, understood as an artifact capable of giving rise to "different ways of seeing and acting in the world", and (b) the effective positioning of the archeology facing the overthrow of the wall.
\end{abstract}

Keywords: The anthropology of archaeology, Fort of Nativity, historical heritage. 


\section{“INDIGITADO ESTRUPÍCIO": ARCHÉOLOGIE ET DE SIGNIFICATIONS SUR LE MUR DU FORT DE LA NATIVITÉ}

\section{Résumé}

Entre 1999 et 2002, le Fort du Presépio à Belém (PA) a été l'objet de recherches multidisciplinaires tournant autour de sa restauration ainsi que dans l'objectif de samuséalisation au sein de la conjoncture du projet "Feliz Lusitânia". L'une des sciences a s'être consacrée à cette recherche est l'archéologie, pour avoir participé de manière significative à la conduite de ce projet. Durant ce processus, une question a pris des dimensions extérieures à la recherche archéologique: la mise-à-terre d'un mur se trouvant entre la rue et la fortification. Dans ce contexte, la paroi était alors considérée comme étant une «fantasmagorie», qui empêchait l'ancienne symbiose entre la forteresse et la ville. Toutefois, la démolition du mur a été une décision prise par défaut par l'équipe d'archéologie, mais également en accord avec les intérêts esthétique-fonctionnels du plan muséologique. Pour justifier cette action, une série de sens furent attribués au-dit "artefact" (erreur grossière et incongrue, aberration). Ceci-dit, ce travail prétend débattre deux aspects: (a) les significations données au mur, considéré comme étant un artefact capable de susciter des "manières distinctes de voir et d'agir dans le monde"; et (b) le positionnement effectif de l'équipe d'archéologie face à la démolition du mur.

Mots clés: Anthropologie de l'archéologie, Fort du Presépio, patrimoine historique. 


\section{INTRODUÇÃO}

O trabalho arqueológico suscita significados que vão além das perspectivas desta ciência. A despeito de seu aparato teórico, conceitual e metodológico, a arqueologia se vê constantemente diante de questões que são inerentes ao seu entorno vivo, ou seja, às pessoas que estão presenciando, de alguma forma, a escavação e por isso criam expectativas acerca dela. Segundo Leone (2008:119 e 129), o que a arqueologia faz não "é ciência das origens", todavia muitos dos seus resultados são usados nesse sentido.

Durante o processo de pesquisa arqueológica do atualmente denominado Forte do Presépio, ${ }^{1}$ uma questão tomou dimensões exteriores à prospecção: a derrubada de um muro que se afigurava entre a rua e a fortificação. Dentro do projeto de restauro e adequação deste espaço, o muro foi entendido como uma "fantasmagoria" (Britto 2009:112) que impedia a antiga simbiose entre a fortaleza e a cidade. Tendo sida criada a partir da fortificação, Belém estava apartada de seu berço de origem, justamente por um artefato que era estranho à função original do prédio (Costa 2007).

A proposta e posterior retirada do muro causaram uma série de debates na sociedade paraense. De acordo com Costa (2007:108), essas discussões encerraram tanto um aspecto políticopartidário, quanto um simbólico, no sentido de apropriação dos emblemas da memória, além do interesse em "monopolizar uma história oficial". Todavia, a demolição do muro foi uma decisão tomada não do ponto de vista arqueológico, mas sim de acordo com os interesses estético-funcionais imbuídos do plano de restauro (Costa 2007).

Os trabalhos por nós analisados, porém, referendam o pouco destaque à posição da arqueologia diante dessa controvérsia (Miranda 2006, 2009; Costa 2007; Britto 2009). Isto posto, pretendemos nesse artigo debater (a) questões relativas aos significados dados ao muro, entendido aqui como artefato capaz de suscitar "maneiras distintas de ver e agir no mundo" (Lazzari 2005:128); e (b) o posicionamento efetivo dos arqueólogos diante da derrubada do muro.

Diante disso, retornamos ao debate de Leone (2008) quanto à autoridade da arqueologia. Segundo esse autor, a ciência arqueológica não é neutra e seus resultados podem afetar de alguma maneira a sociedade contemporânea. Sendo assim, é imperativo que o arqueólogo tome posições pautadas em seus dados científicos (Leone 2008). Por outro lado, pretendemos tecer uma antropologia da arqueologia, no sentido de pensá-la enquanto fenômeno sociocultural contemporâneo (Castañeda 2008).

Por certo, não queremos afirmar que os resultados do trabalho arqueológico tenham de ser definitivos e se sobrepor aos significados que a cultura material tem para a sociedade em geral. Como afirma Lazzari (2005:128), "As coisas possuem uma existência corporal e temporal, uma presença particular de induzir maneiras distintas de ver e agir no mundo". Acrescenta-se que no caso do muro do Forte do Presépio, o conceito de "patrimônio histórico" 
foi colocado em questão, sendo comumente apropriado pelas partes que se polarizaram nesse debate (Costa 2007).

O artigo foi dividido em três seções, além da introdução e conclusão. $\mathrm{Na}$ primeira, tratamos da relação entre o mais recente discurso sobre a fundação de Belém e a criação do Projeto Feliz Lusitânia como referência às origens da cidade; em seguida, analisamos as significações dadas ao muro do Forte do Presépio e a sua demolição no contexto do processo de restauro do mesmo; por fim, mostramos a posição da arqueologia diante da polêmica suscitada com o referido muro.

A pesquisa foi pautada tanto na bibliografia pertinente ao assunto, quanto em alguns documentos produzidos no contexto das pesquisas arqueológicas no Forte do Presépio, especificamente os pertencentes aos arquivos do Instituto do Patrimônio Histórico e Artístico $\mathrm{Na}$ cional (IPHAN/2 $2^{\text {a }} \mathrm{SR}$ ); além disso, nos utilizamos das notícias veiculadas na mídia impressa do período.

\section{FELIZ LUSITÂNIA: HISTÓRIA E MEMÓRIA DA CIDADE}

A historiografia associa a fundação de Belém com o erguimento do Forte do Presépio em 1616, no contexto de consolidação do território ibérico ${ }^{2}$ no que hoje é conhecido como Amazônia. Recentemente, tem-se afirmado que foi a partir dessa fortificação que o núcleo urbano inicial se desenvolveu, obedecendo à prática de criação de cidades portuguesas no mundo colonial (Araujo 1998). Dessa forma, as ruas foram organizadas radialmente, tendo a fortificação como ponto nodal.

“(...) o desenho das ruas da Cidade Velha segue uma intenção radiocêntrica a partir da praça, a praça-dearmas (sic), e o alinhamento da primeira rua coincide com a direcção (sic) cardeal norte-sul. As seguintes correspondem a leves inflexões, uma com inclinação de $5^{\circ}$ e outras duas com inclinações respectivas de $15^{\circ}$ e $35^{\circ}$. O cruzamento de tais ruas radiais é feito por transversais, que cruzam ortogonalmente a rua central, e depois inflexionam para, outra vez, perfazer um ângulo recto (sic) com a via seguinte. A despeito de algumas "falhas" na execução do conjunto, existe no traçado urbano da Cidade Velha de Belém uma clara noção de unidade de desenho" (Araújo 1998:81).

Desse ponto de vista, a cidade foi pensada enquanto núcleo fortificado, um dos responsáveis pela defesa do território, tanto do ponto de vista militar, quanto do político (Meira Filho 1976; Araújo 1998, 2006). Situada entre a baía do Guajará e o rio Guamá, tendo ainda o antigo Pântano do Piri em sua retaguarda, constituía-se com uma cidade "naturalmente" fortificada (Araújo 1998, 2006). Seu primeiro espaço ocupado foi o do bairro hoje conhecido como Cidade Velha - no período colonial chamado de Cidade -, lugar por excelência da administração local, com seus prédios administrativos e eclesiásticos. Ao seu lado, configurava-se a Campina, bairro de vocação comercial por estar mais próximo ao porto, localizado no canal do Piri (Araújo 2006). Até a primeira metade do século XIX, 
o núcleo urbano estendia-se essencialmente nesses dois bairros; apenas a partir dessa centúria as habitações expandem-se efetivamente para as regiões mais distantes.

Se o Forte do Presépio foi o ponto de irradiação da cidade, ele também se constituiu como núcleo de propagação da colonização ibérica, e depois essencialmente portuguesa, pelo Vale Amazônico (Meira Filho 1976; Saragoça 2000; Araújo 2003). Belém, dessa forma, configurou-se como núcleo de poder colonial, posição que ocupou por longo período se pensarmos sua condição de capital ao longo de seus 395 anos. Foi esse cenário inicial o primeiro a receber a denominação Felir. Lusitânia, atribuição dada pelos próprios colonizadores (Saragoça 2000); essa designação, por certo, foi uma síntese ideológica do processo colonial iniciado em 1616, posto que referende a perspectiva expansionista européia em sua toponímia. Desse modo, a referência lusa - católica, monárquica, militar e ocidental - foi posta em protagonismo, enquanto se escamoteou outros agentes e as consequências, nem sempre felizes, desse processo histórico.

A despeito disso, foi com essa denominação que em 1997 começou-se a implementar-se um projeto de revitalização do centro antigo de Belém, a Cidade Velha. Com o objetivo de "suscitar os referenciais históricos, sociais, econômicos e de ocupação territorial da Amazônia e do Pará", bem como "as dimensões urbanísticas, paisagísticas e arquitetônicas da cidade", o Feliz Lusitânia centrou-se na "revitaliza- ção do núcleo histórico da cidade de Belém" (Pará 2002: 1). Com um viés arquitetônico (Costa 2007), o projeto foi delimitado por "centros de interesses",

"que compreendem o atual Forte do Castelo de São Jorge (Forte do Presépio), a Igreja de Santo Alexandre (Igreja de São Francisco Xavier), o atual Palácio Episcopal (Colégio Jesuítico de Santo Alexandre), e o atual Depósito de Mantimentos da Oitava Região Militar (antigo Hospital Militar) e anexos, os jardins e o entorno imediato dessas áreas. São edificações que remontam ao século XVII e início do XVIII, e tem seus limites entre a Baía do Guajará e a Praça Frei Caetano Brandão" (Pará 2002:7).

Nesse projeto, foram previstas cinco etapas, na seguinte ordem: Museu de Arte Sacra (inaugurado em 1998), Casario da Rua Padre Champagnat, Forte do Presépio, Espaço Cultural Casa das Onze Janelas e Casario da Ladeira do Castelo (Pará 2002). Com exceção desta última fase do projeto, todas as outras foram cumpridas, sendo que as segunda, terceira e quarta fases foram feitas concomitantemente, entre 2000 e 2002 (Costa 2007; Brito 2007). Direcionaram-se as intervenções a partir de
“dois princípios básicos: a retirada de todos os acréscimos que agrediam e descaracterizavam as instalações mais originais de cada prédio; e a preserva- ção - às vezes até mesmo valorizada - das alterações promovidas em di- versas épocas, e que foram considera- das como contributivas à artisticidade do conjunto" (Pará 2002: 2).

Todas essas intervenções de restauro 
foram precedidas pelas pesquisas arqueológicas, além de outras de cunho arquitetônico, histórico e urbanístico (Pará 2002; Costa 2007; Britto 2009). As prospecções foram coordenadas pelo arqueólogo Fernando Luis Tavares Marques, vinculado ao Museu Paraense Emílio Goeldi e doutor em História pela Pontifícia Universidade Católica do Rio Grande do Sul (PUC-RS), com especialidade em arqueologia histórica. ${ }^{3}$

Sem dúvida, o trabalho desenvolvido com base na Arqueologia foi fundamental na configuração do Feliz Lusitânia, o que deve ser referendado como uma prática salutar nesse tipo de intervenção. Como consta no Relatório do Monitoramento Arqueológico (Marques 2003), esse tipo de pesquisa afigura-se como uma necessidade:

"Em atenção aos princípios básicos firmados em várias cartas $\mathrm{e}$ documentos de preservação e restauração de patrimônio histórico edificado, o Projeto Feliz Lusitânia, passou a contemplar a investigação arqueológica, para evidenciar elementos indicadores de alterações ocorridas na arquitetura do Forte do Castelo, ao longo de seus quase quatrocentos anos de existência, que nos dias atuais encontravam-se inteiramente despercebidas da leitura que o público faz do monumento" (Marques 2003:11).

Especificamente no espaço do Forte do Presépio, nosso principal interesse neste artigo, essas pesquisas modificaram, inclusive, o projeto inicial (Costa 2007). O objetivo inicial era a elaboração de um museu militar, sendo para isso utilizada a cultura material proveniente do sítio (Marques 2003, 2006). Todavia, algumas estruturas arquitetônicas da fortaleza, além de objetos alusivos à pré-história, provocaram uma inflexão nessa perspectiva inicial (Marques 2003, 2006): os anfiteatros projetados para a parte interna do Forte, bem como o do local onde localizava-se o restaurante foram repensados após a evidenciação de estruturas defensivas, alusivas a tempos diversos; além disso, a cerâmica indígena pré-colonial criou a necessidade de ampliar o recorte temporal do museu, fazendo-se referência aos momentos anteriores à colonização européia - o museu militar transformou-se em Museu do Encontro (Marques 2003, 2006).

Acrescenta-se que pesquisas efetuadas por técnicos do IPHAN demonstraram algumas críticas ao projeto - o que veremos com mais detalhes na seção seguinte -, provocando certas modificações. Uma delas dizia respeito ao espelho d'água que se pretendia criar na área do fosso da fortificação. Segundo parecer de Adler Homero Fonseca de Castro, historiador, e Antonio Aguilera Montalvo, arquiteto, (Iphan 2001) esse era um dos elementos que poderiam provocar um "pastiche histórico", posto que não fizessem parte da configuração arquitetônica das fortificações das colônias portuguesas. De acordo com Miranda (2006), já em janeiro de 2002 esse elemento foi retirado das plantas do projeto endereçadas ao IPHAN.

Sendo assim, vê-se que as pesquisas efetuadas ao longo do trabalho de intervenção na fortificação, em especial as arqueológicas, foram preponderantes no 
resultado alcançado. Não se deve negligenciar que toda a elaboração do projeto foi embasada em investigações, o que não impediu que as "descobertas" arqueológicas provocassem modificações em sua estrutura.

No que diz respeito à arqueologia histórica, é comum que as prospecções evidenciem fatos não informados na documentação histórica; isso decorre, em parte, do caráter mais objetivo da cultura material, se comparado com a subjetividade do registro escrito ou iconográfico, gerando dessa forma outro nível de informação (Orser Júnior 1992; Lima 1993). Neste sentido, observa-se que os condutores do Feliz Lusitânia possuíam certa sensibilidade para levar em consideração essa perspectiva.

Todavia, se o projeto de restauro das edificações gerou várias modificações com "a retirada de todos os acréscimos que agrediam e descaracterizavam as instalações mais originais de cada prédio" (Pará 2002:2), nada gerou mais controvérsias que a demolição do muro que se afigurava entre o Forte do Presépio e a rua que lhe é adjacente. Os embates se deram tanto no âmbito políticopartidário, quanto nos debates dentro dos órgãos de proteção ao patrimônio histórico, seja de nível federal ou municipal (Costa 2007).

No entanto, apesar da questão arquitetônica - ligada ao muro - ter tomando maiores dimensões, pode-se citar outros dois fatos de relevância: o primeiro diz respeito à retirada de peças de artilharia das instalações do Forte do Presépio registrado no "Embargo Extrajudicial n. ${ }^{\circ}$ 009/2000”, datado de 06/10/2000, em que o IPHAN notifica a Divisão do $8^{\circ}$ Departamento de Suprimentos pelas remoções indevidas; outro fato está registrado no Ofício PRDC/PR/PA/N ${ }^{\circ}$ 1408/2008-R (com data de 11/09/2008), emitido pelo MPF/Procuradoria da República no Pará, sobre ossadas de supostos presos políticos encontradas nas imediações do Forte do Presépio; em resposta, a Superintendente do IPHAN afirma que as ossadas são relativas ao período colonial e, portanto, não podem ser de presos políticos (Ofício 438/2008-GAB-2ªR/IPHAN).

Nesse contexto de vozes dissonantes, a que menos foi ouvida foi a da arqueologia. Justamente em uma questão, digamos, mais delicada, não somente pela sua partidarização política, mas também por estar estritamente vinculada à autoridade da ciência arqueológica e das políticas patrimoniais vigentes no país. Esses dois últimos aspectos, diga-se de passagem, construídos com discussões sistemáticas e, a rigor, consolidados no mundo acadêmico.

Antes de tentar responder a esses questionamentos, na próxima sessão vamos discutir os significados dados ao antigo muro do Forte do Presépio, bem como reconstituir seu arruinamento durante esse projeto de restauro.

\section{O "INDIGITADO ESTRUPÍCIO”: "VELHO, MAS NÃO HISTÓRICO"!}

As intervenções no Forte do Presépio no âmbito do Projeto Feliz Lusitânia, não foram criticadas somente quando da destruição do muro. Nesse caso elas partiram dos técnicos relacionados ao órgão maior de proteção ao 
patrimônio, o IPHAN - como citamos anteriormente - e do órgão local, a Fundação Cultural do Município de Belém (FUMBEL). Segundo Costa (2007:85), a primeira consideração da esfera municipal foi feita em 2001, ainda nos trâmites da autorização para a execução das obras, quando aprovou "com restrições" o projeto, dado que apenas as intervenções voltadas para a conservação poderiam ser efetuadas. Após esse momento, ainda segundo esta autora, a FUMBEL se manifestou apenas em março de 2002.

Já o IPHAN, após circulação de ofícios entre a $2^{\circ}$ Superintendência Regional

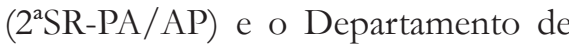
Patrimônio (DEPROT) desta instituição em Brasília, requisitou parecer técnico sobre o projeto do Forte do Presépio (Costa 2007). Em documento de março de 2001 (Parecer n. ${ }^{\circ}$ 25/2001) Adler de Castro e Antonio Montalvo criticaram algumas das propostas presentes no projeto do Forte do Presépio, consideradas como descontextualizadas em uma fortificação: 1) Um talude projetado para o fosso da fortificação; 2) O espelho d'água, como citamos acima; 3) Inserção de meias-luas circulares nas proximidades da ponte que dá acesso à fortificação; além de 3) A reconstrução do parapeitos a barbeta da parte baixa, este por implicar "na escolha de um dado momento histórico em detrimento de outro posterior" (Iphan-Parecer n. ${ }^{\circ}$ 25/2001). Todos esses argumentos foram utilizados para solicitar o embargo administrativo às obras na fortificação. Mas apenas em dezembro de 2001 o IPHAN volta a se manifestar e cobrar um posicionamento da Secretaria de Cultura do Estado (SECULT), quanto aos questionamentos referendados no parecer de Adler de Castro (Costa 2007).

Após essa data a SECULT envia material técnico ao IPHAN e pede reavaliação no projeto (Miranda 2006; Costa 2007). Esse material foi subsidiado pelas pesquisas arqueológicas em andamento e esclarecia o andamento das intervenções, bem como reafirmava o interesse, já contido no projeto inicial, de retirar parte do muro adjacente à Praça Frei Caetano Brandão (Pará 2001). Justificava-se que o muro não fazia parte da construção original da fortificação, posto que impedisse a linha de tiro direcionada para a cidade. Dessa forma propunha-se o rebaixamento do muro,

"conservando o pórtico de entrada, para integrar a fortaleza na visão da praça e abrir um janela da praça para o rio, já que o antigo restaurante do círculo militar [...] vai ser removido e o espaço tratado para contemplação das águas, dos efeitos crepusculares e para espetáculos cênicos" (Pará 2001:4)

Em reportagem de 04 de fevereiro de 2001, é noticiado que, com a destruição do muro que "impede uma nova visão", o "Forte do Castelo vai se integrar à paisagem" (O Liberal/Cartaz 2001:1). Segundo a reportagem, clara alusão às benesses da obra, o Forte "tem se mantido escondido e até esquecido atrás do muro construído na última reforma feita no início do século XIX" (O Liberal/Cartaz 2001:1). A reportagem cita ainda a entrevista com 
a arquiteta Mena Matos, para quem a derrubada do muro permite a abertura do Forte "para os olhos da população no sentido cultural e histórico, para que se conheça um pouco mais sobre a fundação da cidade, resgatando assim a auto-estima tão abalada nos últimos tempos" (O Liberal/Cartaz 2001:1, itálico nosso). Importante destacar a ideia de resgate, posto que ela fosse uma constante nas argumentações sobre a questão. No caso da fala de Mena Matos, o resgate seria da auto-estima, enquanto a matéria jornalística afirma que a reforma "resgata a história da cidade". Por hora, voltemos à questão do muro.

Nessa reportagem há os argumentos essenciais quanto aos motivos da retirada do muro: ele é estranho à arquitetura original do Forte e, portanto, impede que se tenha a visão de conjunto da fortaleza com a Cidade Velha. Todavia, um parecer de Adler de Castro, de fevereiro de 2002, afirma que o muro era elemento integrante da fortificação, inclusive no que diz respeito à sua arquitetura defensiva (Iphan 2002). Para esse técnico do IPHAN, a bateria baixa evidenciada pelas escavações arqueológicas, onde havia o antigo restaurante militar, eram contíguas ao muro. Este, por sua vez, cobria a bateria baixa e teria sido erigido por volta de
1859, momento em que houve novos investimentos nas fortificações pelo Brasil. Sendo assim, o muro foi erguido quando o Forte do Presépio estava em operação (Figura 1).

Os técnicos da $2^{\mathrm{a}}$ Superintendência Regional do IPHAN, em memorando de dezembro de 2002, apóiam a decisão do Superintendente - Luis Severino da Silva Jr. - dessa regional em paralisar os serviços na fortificação, especificamente em decorrência da retirada do muro (IPHAN 2002). Para esses especialistas do IPHAN, estava em curso a inadmissível
“(...) tentativa de imposição de uma proposta de "restauração" equivo- cada que desconsidera os preceitos estabelecidos pelas Cartas Patrimo- niais, bem como indicações técni- cas e conceituais vigentes na área de restauro. Tal afronta fica eviden- ciada, no projeto para o Forte do Castelo, na deformação da escarpa, que recebeu uma saia na área do fosso seco; na eliminação dos rebo- cos das muralhas; na persistência, mesmo diante de todas as infor- mações levantadas nas pesquisas iconográficas e arqueológicas, da proposição de demolição do muro, construído em meados do século XIX, com alvenaria de pedra e cal de sernambi” (IPHAN 2002).

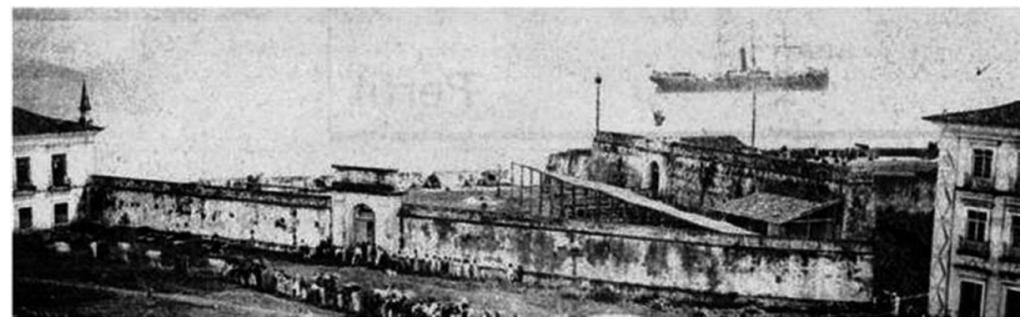

Figura 1. Imagem do Forte em 1884 (Adaptado de Costa 2007:92). 
A despeito dessas argumentações, o projeto foi aprovado na íntegra pelo Diretor do DEPROT (Miranda 2006; Costa 2007). Com isso, a demolição só foi iniciada em 25 de novembro de 2002, sendo que no dia 27 desse mês o Ministério Público Federal (MPF/PA) concedeu liminar cancelando a retirada do muro (O Liberal/Cartaz 2002; Costa 2007). O Tribunal de Justiça do Estado do Pará (TJE/PA), no dia 29, cassa a liminar anterior e as demolições seguiram (Costa 2007). Nesse mesmo dia, a própria Justiça Federal, por meio do MPF/PA, mandou paralisar as obras no "muro frontal do Forte do Castelo" (O Liberal, 2002). No dia 5 de dezembro, o que sobrava da amurada foi definitivamente demolido, por decisão do Tribunal Federal em Brasília (Diário do Pará 2002; O Liberal 2002; Costa 2007), mantendo-se apenas o seu pórtico de entrada e alguns centímetros do muro (Figura 2).

Durante o debate sobre a derrubada do muro efetuado na imprensa, os posicionamentos dos técnicos ligados às instituições patrimoniais, assim como as perspectivas do Governo do Estado exprimidas principalmente pela voz do Secretário de Cultura - , e da própria esfera judicial, foram manifestadas continuamente. Todas elas buscavam justificar a retirada ou manutenção do muro, atribuindo dessa forma significados diversos ao referido artefato.

Neste sentido, os debates desenvolvidos na arqueologia contemporânea tem se esforçado em mostrar a influência da cultura material na sociedade, numa relação de retroalimentação en- tre sujeito e objeto. Miller (1987:121) observa que os objetos não são apenas referências de um grupo social, já que eles podem ser "constitutivos de certas relações sociais". Nessa linha de pensamento, Lima (2011) afirma que a cultura material desempenha papel ativo nos sistemas sócio-culturais. Logo, os objetos não são agentes meramente passivos.

De toda forma, há constantes atribuições aos objetos, como argumenta Hilbert (2006). Além disso, os significados vão mudando ao longo da vida dos objetos (Lima 2011), posto que ele perca e incorpore atributos, passa por "redes de significados que o classificam e o reclassificam em categorias consti-

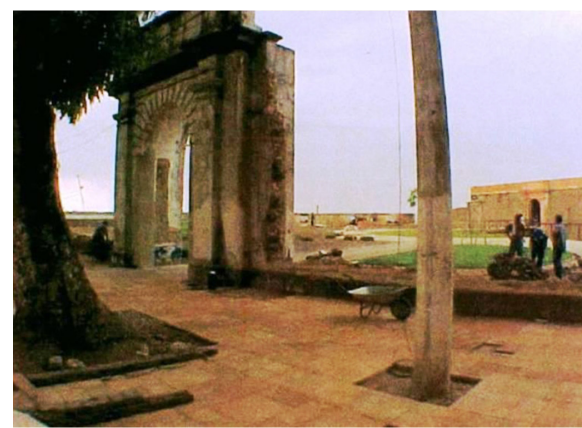

Figura 2. Imagem do pórtico já sem o muro (Adaptado de Costa 2007:97)

tuídas culturalmente" (Rede 1996:276) e, dessa forma, suscitam alterações na sua biografia. Zarankin (2008:326), ao discutir a arquitetura como discurso material, menciona que os "edifícios são objetos sociais" e por isso "estão carregados de valores e sentidos particulares". Logo, as construções têm uma participação ativa na formação da sociedade (Zarankin 2008). 
Tendo isto em vista, podemos discutir os significados atribuídos ao muro do Forte do Presépio. Como vimos, houve por parte dos técnicos do IPHAN e, acrescentemos, da FUMBEL, o interesse em deixar claro que o muro constituía parte do patrimônio histórico e, portanto, deveria ser mantido e inserido nas adaptações realizadas na fortificação (Costa 2007). Os argumentos, nesse sentido, voltaram-se para os referenciais históricos e arqueológicos na tentativa de legitimar tais considerações.

Por outro lado, as argumentações do setor favorável à retirada do muro também se utilizaram de dados científicos; todavia, é interessante observar as adjetivações efetuadas por essa parcela de agentes interessados nessa opção mais drástica. Por desencadear um debate intenso entre a Prefeitura de Belém e o Governo do Estado, com ativa participação do IPHAN, o artefato foi denominado de "muro da discórdia" (Miranda 2006; Costa 2007).

Segundo Costa (2007), o conflito político-partidário deu a tônica dos debates divulgados pela imprensa. As alusões partidárias, contudo, apareceram de forma patente nas argumentações do Secretário de Cultura, Paulo Fernandes Chaves, para quem o "principal motivo para o embargo da demolição do muro" foi político (O Liberal/Cartaz 2002:1). Segundo Paulo Chaves, o próprio Superintendente da $2^{a}$ SR IPHAN, Luiz Severino Jr. de origem pernambucana -, possuía filiação com um partido político de oposição ao Partido Social Democrata Brasileiro (PSDB), o qual governava o estado do Pará, e por isso tratava o assunto com "má vontade" (O Liberal/ Cartaz 2002:1). Além disso, o Secretário acusou o Superintendente de não ter um conhecimento plausível sobre a questão, posto que apenas "pegou carona na opinião de historiadores contrários à derrubada do muro" (Chaves citado em O Liberal/Cartaz 2002:1; Diário do Pará/Cidades 2002:6).

Além disso, o então chefe da SECULT afirmou que "a derrubada do muro dá mais visibilidade à obra, destaca todo o conjunto que está sendo feito e isso incomoda" (Chaves citado em O Liberal/ Cartaz 2002:1; Diário do Pará/Cidades 2002:6). A partir desse momento, Paulo Chaves começa a atribuir significados classificatórios ao muro, dotando este objeto de vida própria, de acordo com os termos desse contexto. ${ }^{4}$

Como mostramos na seção anterior, o Forte do Presépio, de acordo com os estudos de Araújo (1998, 2003, 2006), influenciou diretamente na organização espacial da Belém colonial. Partindo dessa premissa, o projeto Feliz Lusitânia pretendeu restabelecer esta antiga ligação entre a fortificação e a cidade (Miranda 2006; Costa 2007). Segundo Paulo Chaves, o a fortaleza perdeu sua função defensiva em meados do século XIX, ao passo que perdia também "a posição protagonista da história de Belém para ser coadjuvante de segunda classe até se modificar totalmente para uma sede social voltada aos militares" (Diário do Pará/Cidades 2002:6).

O muro, nesse contexto, passou a sombrear o Forte (Diário do Pará/ Cidades 2002:6). Paulo Chaves, em 
texto publicado em jornal de grande circulação, ${ }^{5}$ afirmava que deveria-se "comemorar a parcial demolição da muralha" - batizada de "indigitado estrupício", "estrovenga" e "aberração" -, já que ele "nunca fez parte do Forte do Presépio”, tendo a função tão somente de ocultar "a presença monumental" da fortaleza (O Liberal/Cartaz 2022:1). Nas palavras do Secretário, o muro constituía-se como uma

“(...) barreira física que impedin o acesso da população às cercanias do Forte e a fruição visual da sua presença no cenário da vida cotidiana, e da baía do Guajará ao fundo, lhe servindo de moldura, produðiu também a desvalorização do monumento, acentuando o processo de decadência. Indefeso pelo ocultamento, ele tornou-se "presa fácil" para formas de utilização inadequadas e espúrias, como, por exemplo, a instalação em seu recinto de uma edificação da Companhia inglesa Port of Pará (sic), destinada ao gerenciamento da montagem dos galpões portuários, durante os anos de 1907 a 1920, e, mais recentemente, a sede do Círculo Militar, o cassino dos oficiais e apartamentos para oficiais em trânsito" (O Liberal online/Cartaz, itálico nosso).

Sendo assim, o muro não apenas foi uma barreira física, mas ele tinha o poder de ação sobre o Forte, posto que produzia, acentuava e ocultava a desvalorização e a decadência. Logo, o muro agia como algoz da fortificação, justamente por deixá-lo escondido (O Liberal online/Cartaz 2002). O muro foi associado às outras "aberrações" retiradas no início do processo de restauro (O Liberal online/Cartaz 2002), tais como o restaurante do Círculo Militar, o cassino e as hospedarias de trânsito dos militares (Diário do Pará/Cidades 2002:6). A permanência da "estrovenga" até o fim da obra não por outro motivo senão o de servir de "tapume e proteção do canteiro de serviços" (O Liberal online/Cartaz 2002).

A retirada desse "entulho visual" (O Liberal online/Cartaz 2002) reconstituiu "o papel que o forte" já possuiu "como parte de toda a área" (O Liberal/Cartaz 2002:1). Além disso, recuperou-se o "olhar perdido" e a "simbiose entre o forte e a cidade, que se perdeu a partir do século XIX, quando o sítio do entorno imediato do forte transformou-se em quartel" (Chaves apud O Liberal/Cartaz 2002:1). Na conjuntura de retirada do muro, esses significados foram reproduzidos na decisão judicial que autorizou o ato.

A desembargadora Selene Maria de Almeida, do Tribunal Regional Federal da $1^{a}$ Região, foi quem deliberou sobre a questão, com base no material entregue pela SECULT nos autos do processo (Costa 2007). Para a desembargadora, o muro não fazia parte da fortificação por ter sido construído 250 anos depois de sua fundação; logo, o que estava sendo levado a cabo pelos governantes estaduais era o resgate da "história da cidade através da recuperação do seu patrimônio colonial urbanístico, que a falta de consciência estética e histórica dos administradores de 1860 não atinava (sic)" (apud O Liberal/Cartaz 2002:1; Miranda 2006:209). Por fim, "o muro é velho, mas não histórico” (apud O Liberal/ 
Cartaz 2002:1) e o "que é histórico e deve ser protegido é o sítio do Forte e prédios vizinhos separados por um muro hoje destituído de finalidade" (O Liberal online/Cartaz 2002).

A noção de resgate é retomada nas palavras da desembargadora, com já vinha sendo feito durante as obras na fortificação (O Liberal/Cartaz 2001:1). Segundo Costa (2007), essa ideia está relacionada com o discurso patrimonial imprenso no Feliz Lusitânia; assim, tentou-se justificar e legitimar a intervenção efetuada nas edificações inseridas nesse projeto, ao passo que se tentava dotá-las de identidade e coletividade na sociedade paraense, especialmente a de Belém.

Denotativamente, a palavra resgatar está associada à recuperação, salvamento "de situação perigosa" ou "acontecimento nefasto" (Ferreira 2001:600). No caso da restauração do Forte do Presépio, o que se pretendia não era apenas o resgate da história do prédio, mas a da própria cidade, assim como da auto-estima dos cidadãos. Tendo em vista as atribuições dadas ao muro frontal da fortificação, podemos supor que justamente esse "estrupício" foi o responsável pela ameaça à história e à auto-estima colocadas em questão. E mais, não poderia haver o resgate desses aspectos sem a extinção dessa "aberração". Deixa-se, contudo, os espólios da "estrovenga", transformado em "arco do triunfo" - ou Portal do Aquartelamento (Miranda 2006). O artefato danoso, então, foi convertido e expurgado de suas atribuições ameaçadoras.

O novo projeto arquitetônico do Forte do Presépio do século XXI, com a retirada do seu muro, configura a "construção física da paisagem" (Zarankin 2008:325), no sentido de uma legitimação do poder e tentativa consciente de formar pessoas. Neste sentido, tanto o muro como a fortificação, imbuídos na categoria de patrimônio histórico e cultural, atuaram como elementos mediadores entre os domínios sociais e simbólicos, constituindo, como afirma Gonçalves (2005:16 e 20), pontes entre "categoriais cruciais, tais como passado e presente" ou ainda "entre a história e a memória".

Desse modo, podemos ter uma perspectiva para a explicação das atribuições de sentido dadas ao muro e as várias encarnações que ele passou a receber no contexto contemporâneo. Ressalta-se que esses significados não correspondem, necessariamente, aos existentes durante o erguimento do muro na década de 1860, posto que ele pudesse ser mais um elemento defensivo da arquitetura militar do Forte do Presépio, como apontaram os técnicos do IPHAN; ou, que seja, um muro com suas funções de muro. De qualquer forma, ele possuía uma interação social com as pessoas que o circundaram durante esses anos, posto que fosse um elemento da paisagem urbana de Belém.

\section{A VOZ ROUCA DA ARQUEOLOGIA}

No contexto de derrubada da amurada do Forte do Presépio, Paulo Chaves argumentou que todas as decisões a respeito da obra, inclusive esta, foram tomadas de acordo com "critérios 
artísticos, históricos e arqueológicos" (O Liberal/Cartaz 2002:1). Como afirmamos anteriormente, as pesquisas em arqueologia foram essenciais dentro do projeto Feliz Lusitânia, chegando a mudar as projeções museológicas iniciais para a fortificação. Vários outros campos do conhecimento também contribuíram nesse sentido.

Durante a questão do muro, alguns dos profissionais envolvidos no projeto se manifestaram a favor de sua retirada. Esse é o caso, por exemplo, de Geraldo Mártires Coelho, ${ }^{6}$ para quem o trabalho no Feliz Lusitânia foi permeado sempre de "critérios os mais reconhecidos possíveis" (citado em Costa 2007:117). Sem nominar o muro, mas dirigindo-se à Superintendente do IPHAN em defesa das ações da SECULT, o historiador sentencia e alerta: "Maior que os homens e maior ainda que as circunstâncias é a História. Todos passaremos. Soberana, sem dúvida, ficará a escrita de Clio, o espelho de seu tribunal" (citado em Costa 2007:117). Em dissertação defendida em 2009, Rosangela Marques de Britto, museóloga atuante no projeto em discussão, posicionou-se "a favor da retirada de parte do muro" (Britto 2009:116).

Britto (2009) afirma ainda que se fosse consultada, provavelmente, a população decidiria pela derrubada do muro, já que a sociedade recebeu bem a nova "paisagem". Todavia, Miranda (2006) mostra que a recepção dos habitantes de Belém quanto ao Feliz Lusitânia não foi unívoca. No que diz respeito ao muro, muitos dos moradores da Ci- dade Velha sentiram-se ofendidos com a sua demolição.

Sendo assim, a retirada do muro gerou uma série de controvérsias pouco comuns quando se pensa nas intervenções em patrimônios históricos no Brasil. Cabral (2010) evidencia outro exemplo similar, ocorrido em Recife, quando da restauração do edifício Luciano Costa: por ser de arquitetura eclética, esse prédio acabou por perder alguns de seus elementos após a intervenção. Isso gerou, segundo Cabral, grande repercussão e a mobilização de diversos agentes.

Seja no caso de Recife, ou no ocorrido em Belém, houve posicionamento dos profissionais envolvidos nas intervenções, o que não significa sempre unanimidade. Todavia, apesar das afirmações do Secretário de Cultura, mostradas no início dessa seção, não se vê nos registros do Feliz Lusitânia a formalização do parecer da arqueologia sobre a questão do muro. Ao analisar esse material, ao lado da bibliografia que já tratou do tema, observa-se que não havia por parte da equipe de arqueólogos interesse na derrubada no muro.

No projeto inicial apresentado por Fernando Marques ao IPHAN, ${ }^{7}$ o grande objetivo das escavações era o seguinte: "Resgate de informações arqueológicas que possam subsidiar a compreensão do processo histórico ocorrido na configuração arquitetônica do Forte do Castelo, bem como os meios de vida dos habitantes do local e entorno" (Marques 2000:3).

Além disso, pretendia-se "verificar a 
localização de indícios [...] de elementos arquitetônicos detectados $\mathrm{m}$ iconografia dos séculos XVIII e XIX", de um baluarte voltado para o continente, uma casa de pólvora de forma circular, a Capela de Santo Cristo, fornos de cal, alinhamento dos quartéis, as fundações do parapeito curvo, e paredes da cortina (Marques 2000:3).

Assim, as áreas de prospecção foram definidas dentro do espaço "aquartelado" pelo muro, mas não em função deste. ${ }^{8}$ Ao todo, foram definidas cinco áreas de escavação no Forte do Presépio, sendo que uma delas foi a denominada "área da capela", "localizada defronte o Forte, onde existiam os prédios do Restaurante do Círculo Militar e do Cassino dos Oficiais" (Marques 2003:13), próxima ao muro que separava a fortificação da Praça Frei Caetano Brandão.

Em memorando enviado por Luiz Severino, Superintende da $2^{\mathrm{a}} \mathrm{SR} / \mathrm{IPHAN}$, ao diretor do DEPROT/IPHAN-DF, quando já havia sido feita algumas retiradas do muro, afirma-se que "o arqueólogo responsável pela pesquisa também é contrário à sua demolição" (citado em Costa 2007:88). Além dessa manifestação indireta, no Relatório de Monitoramento Arqueológico é referendado o muro enquanto elemento integrante do Forte do Presépio. Essas conclusões foram obtidas por meio das pesquisas iconográficas, em plantas de 1869 e 1870.

"No documento 'Planta das Posições Relativas do Forte do Castelo, Enfermaria Militar e Arsenal de Marinha', de 1869, percebe- se a projeção da área construída dos aposentos do forte com formato 'L', o parapeito apresentando forma curva, indicação possível de rampa, além dos contornos da lateral do fosso, e do cais voltado para a baía. Observa-se ainda a delimitaşa frontal do terreno do Forte, que seria o muro do aquartelamento, separando-o da Enfermaria, que era o antigo Hospital Militar" (Marques 2003:42, itálico nosso).

Já na planta de 1881, analisada pela equipe da arqueologia, observa-se a "área frontal [do Forte] delimitada pelo muro do aquartelamento. Neste espaço, junto à orla da baía do Guajará, se destaca o que parece ter sido uma construção linear disposta entre o Forte e o Hospital Militar"' (Marques 2003:43).

Por essas informações, deduz-se que houve interesse por parte da equipe dirigida por Fernando Marques em deixar claro que o muro integrava a estrutura arquitetônica da fortificação, mesmo que ele não fosse referente ao século em que foi construído o Forte. A pesquisa arqueológica, nesse sentido, se utilizava da perspectiva de resgate, mas em um sentido específico, qual seja o "de buscar características através da arqueologia, que estavam ocultas, que não estavam visíveis e que pudessem compreender aquilo como realmente um forte" (Marques 2003 apud Costa 2007:130).

Ao que parece, o muro no contexto do século XIX, caracterizava o Forte do Presépio enquanto fortificação ativa que era. Todavia, como já nos referimos antes, a perspectiva da arqueologia não foi levada em consideração 
quando se decidiu, e insistiu, em derrubar o muro.

Apesar das afirmações reiteradas do Secretário de Cultura, além dos posicionamentos favoráveis de outros integrantes da equipe do Feliz Lusitânia, quanto ao subsídio da arqueologia na decisão sobre o muro, não se vê um posicionamento nesse sentido por parte de Fernando Marques e equipe. Todavia, o muro foi demolido e a vOz da arqueologia, tão atuante na conformação das projeções da museografia do Forte do Presépio, foi passada despercebida, talvez por ter sido discreta nesse momento, deve-se ressaltar.

De qualquer forma, a autoridade da arqueologia foi posta em questão. Sem dúvida, como afirma Trigger (2004:15), "os arqueólogos não podem esperar que se estabeleçam relações unívocas entre determinadas interpretações arqueológicas e interesses particulares de classe". Para esse autor, os arqueólogos devem sim analisar a forma como suas considerações são utilizadas pela sociedade para alçarem seus "objetivos em determinadas situações" (Trigger 2004:15).

Isso não significa uma defesa da neutralidade, se é que ela é possível, pois como aponta Leone (2008), a arqueologia deve ter posicionamentos políticos, posto que isso ajude, inclusive, a fortalecer sua autoridade. Pesquisas arqueológicas recentes têm mostrado o quanto é válida a tentativa de observar os interesses da sociedade do entorno das escavações, havendo atenção para as diversas explicações dadas ao registro arqueológico (Silva 2002; Hodder
2003; Baeta \& Mattos 2007; Leone 2008; Gnecco \& Hernández 2008). Por certo, essa é uma prática mais difundida nas pesquisas junto às populações indígenas, sendo também comum nos trabalhos de etnoarqueologia.

Todavia, Castañeda (2008) destaca que a prática de uma etnografia arqueológica, em que esta própria ciência é sujeita à etnografia, é extremamente salutar nos trabalhos no sítio. Assim, a etnografia teria o papel de elucidar tanto o "passado arqueológico quanto o contexto social, a dinâmicas e processos da arqueologia do presente" (Castañeda 2008:30). Assim, essa é uma perspectiva que pode ser aplicada nas pesquisas de arqueologia histórica em centros urbanos, como foi o caso do trabalho no Forte do Presépio.

Como afirmamos anteriormente, a derrubada do muro causou impacto na sociedade em geral (Miranda 2006). Logo, não se pode pensar que ele foi apenas um "muro metafórico", como afirmou Britto (2009), que dividia partidos e posições políticas em âmbito local. Basta lembrar que os registros dos visitantes do museu foram constantes em afirmar o prejuízo da ausência do muro (Costa 2007).

\section{CONCLUSÕES}

Nosso objetivo neste artigo foi analisar os significados que envolveram o muro do frontal do Forte do Presépio durante o processo de restauro do mesmo. Dentre as ciências que contribuíram para conformação deste projeto, a arqueologia possuiu papel de destaque, até o momento em que sua opinião não foi tão interessante. 
A derrubada do muro constituiu-se uma opção estética, com argumentações de fruição de paisagem e valorização do prédio da fortificação. Assim, o muro foi transformado em agente de degeneração e ofensa à monumentalidade da fortaleza.

Por certo, a pesquisa efetuada aqui não esgota o tema, senão apenas abre possibilidades para um estudo mais sistemático. Outros pesquisadores já se debruçaram sobre a questão da Feliz Lusitânia contemporânea, tendo em vista as perspectivas da Antropologia (Miranda 2006), da História (Costa 2007), da Geografia (Brito 2007) e da Museologia (Britto 2009).

Carece, todavia, uma abordagem sob o prisma da Arqueologia que tome como foco as atribuições e sentidos dados às pesquisas e intervenções efetuadas por esta ciência. Este artigo foi uma tentativa inicial nesse sentido.

\section{AGRADECIMENTO}

A primeira versão deste artigo foi produzida no âmbito da disciplina "Fundamentos da Arqueologia", ministrada pela Profa Dra . Márcia Bezerra no Programa de PósGraduação em Antropologia da UFPA.

Agradeço à CAPES pela concessão de bolsa de mestrado (2011-2012).

\section{NOTAS}

${ }^{1}$ O Forte do Presépio foi tombado pelo órgão federal de proteção ao patrimônio histórico e artístico, naquela época SPHAN, em 28 de agosto de 1962 (Costa 2007); além disso, o prédio é protegido pela
Lei 7.709/1994, que regula o patrimônio histórico, artístico, ambiental e cultural de Belém (Miranda 2006). Ao longo de sua existência foi denominado de diversas formas: Forte do Presépio - primeiro nome -, Forte do Castelo, Forte de Santo Cristo, Forte do Pará. Com o restauro do prédio, o nome primitivo foi restabelecido.

${ }^{2}$ Fala-se em expansão ibérica, e não somente portuguesa, porque este período está inserido no percurso político compreendido como União Ibérica (15801640). Nesses anos, em decorrência de uma crise sucessória em Portugal, a coroa de Espanha passou a governar sobre todo o mundo ibérico (Botelho \& Reis 2006).

3 Informações retiradas de: <http://buscatextual.cnpq.br/buscatextual/visualizacv. jsp?id=K4787257D9> Acesso em: 02 jun. 2011.

${ }^{4}$ Não podemos desconsiderar que havia, de alguma forma, divergências políticopartidárias em Belém. A cidade era governada pelo Partido dos Trabalhadores (PT), enquanto que o estado estava sendo encabeçado pelo PSDB. Costa (2007) e Britto (2009) mostram como essa oposição se incorporava também nos discursos acerca das praticas do urbanismo em Belém, onde cada grupo tentava deixar sua marca.

5 Texto também publicado no livro que registra o processo de efetivação do Projeto Feliz Lusitânia (Secult 2006).

${ }^{6}$ Geraldo Coelho é professor na Universidade Federal do Pará e, nesse período, dirigia o Arquivo Público do Estado do Pará, vinculado à SECULT; também prestou consultoria ao Feliz Lusitânia (Costa 2007).

7 Este projeto integra o Processo n. 01492.000075/2000-77-IPHAN.

${ }^{8}$ No bojo da pesquisa no Forte do Presépio, foram realizadas escavações no antigo Hospital Militar, hoje conhecido como Casa das Onze Janelas (Marques 2003, 2006). 


\section{REFERÊNCIAS}

Araujo, R. M. de. 1998. As cidades da Amazônia no século XVIII: Belém, Macapá e Maz̧agão. Porto: FAUP Publicações.

2003. A razão na selva: Pombal e a reforma urbana da Amazónia. Revista Camões 15(15):151-165.

2006. O presépio da Feliz Lusitânia, in Feliz Lusitânia: Forte do Castelo, Casa das Onze Janelas, Casario da Rua Padre Champagnat. Editado por Secretaria Executiva de Cultura do Estado do Pará, pp. 11-19. Belém: SECULT.

Baeta, A. \& M. I. M. Matos. 2007. A Serra da Onça e os índios do rio Doce: uma perspectiva etnoarqueológica e patrimonial. Habitus 5(11):39-62.

Brito, L. S. A. 2007. A intervenção no Centro Histórico e a reorganização sócio-espacial do bairro da Cidade Velha - Belém/PA. Dissertação de Mestrado, Programa de Pós-Graduação em Geografia, Universidade Federal do Pará, Brasil.

Britto, R. M. 2009. A invenção do patrimônio bistórico musealizado no bairro da Cidade Velha de Belém do Pará, 1994-2008. Dissertação de Mestrado, Programa de Pós-Graduação em Museologia e Patrimônio, Universidade Federal do Estado do Rio de Janeiro, Brasil.

Castañeda, Q.E. 2008. The "ethnographic turn" in archaeology: research positioning and reflexivity in ethnographic archaeologies, in Ethnographic archaeologies: Reflections on stakebolders and archaeological practices. Editado por Q. E. Castañeda \& C. N. Matthews, pp. 119-138. Altamira Press: Lanham.

Costa, D. F. da. 2007. Além da Pedra e Cal: a (re)construção do Forte do Presépio (Belém do Pará, 200-2004). Dissertação de Mestrado, Programa de Pós-Graduação em História Social da Amazônia, Universidade Federal do Pará, Brasil.
Ferreira, A. B. de H. 2001. O minidicionário da língua portuguesa. Rio de Janeiro: Nova Fronteira.

Flávio, L. 2002. Patrimônio histórico nas mãos do Iphan. Diário do Pará, Belém, 28 de nov., Cidades, p. 06.

Gnecco, C. \& C. Hernandez. 2008. History and its discontents: Stone statues, native histories, and archaeologists. Current Anthropology 49(3):439-466.

Gonçalves, J. R. S. 2005. Ressonância, materialidade e subjetividade: as culturas como patrimônios. Horizontes Antropológicos 23:15-36.

Hilbert, K. 2006. Qual o compromisso social do arqueólogo brasileiro? Revista de Arqueologia 19:89-101.

IPHAN. Processo n. ${ }^{\circ}$ 01492000075/2000-77IPHAN.

Processo de n ${ }^{\circ} 01492.4000026 / 2001$ -15-IPHAN.

Lazzari, M. 2005. The texture of things: objects, people, and landscape in northwest Argentina (First Millennium A.D.), in Archaeologies of Materiality. Editado por L. Meskell, pp. 126-161. Malden: Blackwell.

Lima, T. A.. 2011. Cultura material: a dimensão concreta das relações sociais. Boletim do Museu Paraense Emílio Goeldi. Ciências Humanas 6(1):11-23.

Leone, M. P. 2008. The foundations of archaeology, in Ethnographic Archaeologies: reflections on stakeholders and archaeological practices, Editado por Q.E. Castañeda \& C. N. Matthews, pp. 119-138. Altamira Press: Lanham.

Marie, F. 2002. TRF autoriza derrubada do muro. Diário do Pará, Belém, 06 dez., Cidades, p. 05.

Marques, F. L. T. 2006. Investigação arqueológica na Feliz Lusitânia, in Feliz Lusitânia: Forte do Castelo, Casa das Onze Janelas, Casario da Rua Padre Champagnat. Editado por Secretaria Executiva de Cultura do Estado do 
Pará, pp. 147-187. Belém: SECULT. 2003. Pesquisa Arqueológica na área do Forte do Castelo em Belém, PA. Monitoramento arqueológico. Belém: Instituto do Patrimônio Histórico e Artístico Nacional. 2000. Prospecção arqueológica na área do Forte do Castelo, em Belém, Pará. Projeto. Belém: Instituto do Patrimônio Histórico e Artístico Nacional.

Meira Filho, A. 1976. Evolução histórica de Belém do Grão-Pará. Belém: GRAFISA.

Miller, D. 1987. Material culture and mass consumption. Oxford: Blakwell.

Miranda, C. S. 2009. Entre a Cidade Velha e a Feliz Lusitânia: Visões sobre o patrimônio cultural em Belém, in Paisagem e cultura: dinâmica do patrimônio e da memória na atualidade. Editado por F. A. da Silveira \& C. D. Cancela, pp. 197-213. Belém: EDUFPA.

2006. Cidade Velha e a Feliz Lusitânia: cenários do patrimônio cultural de Belém. Tese de Doutorado, Programa de Pós-Graduação em Ciências Sociais, Universidade Federal do Pará, Brasil.

Nunes, E. 2002. Prefeitura e governo lutam pelo muro do Forte. Diário do Pará, Belém, 27 nov., Cidades, p. 01.

O LIBERAL. 2002. Justiça embarga derrubada no Forte do Castelo. O Liberal, Belém, 27 nov., Cartaz, p. 01.

2002. IPHAN nega ter autorizado derrubada do muro. O Liberal, Belém, 28 nov., Cartaz, p. 01.

2002. Fumbel processa Secult por derrubar muro do Forte. O Liberal, Belém, 07 dez., Cartaz, p. 04.

Orser Jr., C. E. 1992. Introdução à Arqueologia Histórica. Belo Horizonte: Oficina de Livros.

PARÁ/SECULT. Feliz Lusitânia (Tomo I, Tomo II, Tomo III, Projeto Forte do Castelo
- Memorial Descritivo e Justificativo e Projeto Forte do Castelo anexos de I a VIII).

Paula, F. de. 2002. Justiça autoriza e Secult derruba muro do Forte. O Liberal, Belém, 06 dez., Cartaz, p. 01

Rede, M. 1996. História a partir das coisas: Tendências recentes nos estudos de cultura material. Anais do Musen Paulista (4):265-282.

Saragoça, L. 2000. Da Feliz. Lusitânia aos confins da Amazônia (1615-1662). Lisboa: Edições Cosmos.

Silva, F. A. 2002. Mito e arqueologia: A interpretação dos Assurini do Xingu sobre os vestígios arqueológicos encontrados no Parque Indígena Kuatinemu-Pará. Horizontes Antropológicos 18:175-187.

Trigger, B. 2004. História do pensamento arqueológico. São Paulo: Odysseus.

Vaz, E. 2001. Reforma do Forte do resgata história da cidade. O Liberal, Belém, 04 fev., Cartaz, p. 01.

Zarankin, A. 2008. Los guardiones del capital: arqueologia de la arquitectura de los bancos de Buenos Aires, in Sed non Satita II: Acercamientos sociales em la arqueologia latino-americana. Compilado por F. A. Acuto \& A. Zarankin, pp. 325-339. Córdoba: Encuentro Grupo Editor.

Recebido em 28/05/2011.

Aprovado em 10/08/2011. 